\title{
Investigação das concepções sobre higiene e uso de metodologias alternativas
}

\section{Research into conceptions about hygiene and use of alternative methodologies}

\author{
Andréa Inês Goldschmidt ${ }^{1}$ \\ José Luiz Goldschmidt Júnior ${ }^{2}$ \\ Angela Michelotti ${ }^{3}$ \\ Vagner Silva ${ }^{3}$ \\ Elgion Lucio da Silva Loreto ${ }^{4}$
}

\section{Resumo}

Este artigo relata a investigação sobre higiene, com uma amostra de 19 alunos de anos iniciais em uma escola privada de Cachoeira do Sul, Rio Grande do Sul, Brasil. Tem por objetivo investigar as concepções espontâneas sobre a higiene e identificar as contribuições de um método de ensino, centrado numa abordagem lúdica de educação, para o ensino e a aprendizagem de crianças na área da saúde. Como método de estudo, foi aplicada uma atividade prática com a turma pesquisada. As principais percepções assinalam que atividades práticas desenvolvidas facilitam a aprendizagem, possibilitam maior envolvimento, permitem momentos de distração, possibilitam revisão de conteúdos e necessitam de conhecimentos prévios. Com base nestes resultados são apresentadas algumas implicações educativas para discussão nos anos iniciais.

Palavras-chave: conceitos prévios, higiene e metodologia de ensino.

\section{Abstract}

This paper shows the results of research about hygiene. The sample group was from a school in the municipality Cachoeira do Sul, Rio Grande do Sul, Brasil. The group studied was composed of 19 pupils from both the nursery and basic education phases of the school. This study aims to research of spontaneous conceptions and propose a roadmap of activities on identify the contributions of a teaching method, centered in a ludic education approach, for the teaching and learning of students in the health area. To assess the responses from the children, an interview was made using an experimental methodology was applied with one of the groups surveyed. Students who participated in the methodological activity, were interviewed again. The main perceptions showed that the developed game made the learning process easier and allowed a stronger involvement, moments of distraction and enabled subjects review and it showed that previous knowledge was demanded. Based on these results some educational implications are presented for discussion in the early years.

Keywords: previous conceptions, hygiene, teaching methodology.

\footnotetext{
${ }^{1}$ Universidade Federal de Goiás.

${ }^{2}$ Mestre em Engenharia Agrícola pela Universidade Federal de Santa Maria.

${ }^{3}$ Graduandos em Ciências Biológicas, Universidade Luterana do Brasil, Campus Cachoeira do Sul.

${ }^{4}$ Universidade Federal de Santa Maria.
} 


\section{Introdução}

A Educação está passando por uma transformação que transcende a sala de aula e busca acompanhar a globalização. Nenhum aprendizado tem valor de forma isolada, a informação exige a contextualização. O ensino de Ciências não é diferente e deverá atender igualmente a esta necessidade de mudanças.

Infelizmente, muitas práticas, ainda hoje, fundamentam-se na mera transmissão de informações, sendo a transcrição do livro didático no quadro um recurso ainda predominante na prática de muitos professores e o estudo das Ciências, sem interação com os fenômenos naturais ou tecnológicos, tem deixado enorme lacuna na formação dos estudantes.

Assim, é fundamental discutir o trabalho do professor e estimular para a prática de um ensino voltado a um processo que envolva não só a transmissão de conhecimentos, mas, sobretudo, a competência pedagógica, em que o aprender sobrepõe o ensinar e, consequentemente, onde o aluno é o agente deste aprendizado.

Nesse sentido, as propostas para renovação do ensino de Ciências orientam-se, atualmente, pela necessidade do currículo responder ao avanço do conhecimento científico, valorizando a participação ativa do estudante, através de discussões, experimentação, dinâmicas de grupo, entre outras. Porém, o simples uso das estratégias de ensino não garante, isoladamente, sua relação com a estrutura cognitiva do sujeito da aprendizagem. É fundamental a interação e mediação do professor, para que as estratégias usadas possam garantir situações potencialmente adequadas ao desenvolvimento da Aprendizagem Significativa.

De acordo com Ausubel, Novak e Hanesian (1980), a Teoria da Aprendizagem Significativa teve seu início nos trabalhos de David Ausubel, em 1963, tendo sido desenvolvida por seus seguidores, a exemplo de Joseph Novak e Marco Antonio Moreira. A ideia fundamental da teoria de Ausubel é a de que a Aprendizagem Significativa é um processo em que as novas informações ou os novos conhecimentos estejam relacionados com um aspecto relevante, existente na estrutura de conhecimentos de cada indivíduo. Ou seja, o princípio norteador da teoria de Ausubel baseia-se na concepção de que, para que ocorra a aprendizagem, é necessário partir daquilo que o aluno já sabe.

Os mesmos autores preconizam que os professores/educadores devem criar situações didáticas com a finalidade de averiguar esses conhecimentos, que foram designados por ele mesmo como conhecimentos prévios. Estes seriam os suportes em que o novo conhecimento se apoiaria. Esse processo foi designado por eles próprios como ancoragem.

Tortori (2005) aponta que esta teoria difere da aprendizagem memorística, que se caracteriza pela absorção literal e não substantiva do novo material, gerando interações fracas com a estrutura cognitiva. Contrariamente, a Aprendizagem Significativa visa uma interação mais plena e inter-relacionável de um novo saber com a matriz cognitiva, gerando vínculos mais estáveis e indissociáveis.

Demczuk, Sepel e Loreto (2007) abordam que o ensino de Ciências pode desenvolver um importante papel para proporcionar aos alunos uma ampla mostra de experiências. Isso pode fazer com que os estudantes passem a refletir mais sobre suas interpretações, abrindo um novo horizonte de conhecimento e incentivando-os à constante pesquisa, em busca de novas ideias sobre o mundo em que vivem. 
Quando a criança inicia sua vida escolar traz consigo a valoração de comportamentos favoráveis ou desfavoráveis à saúde oriundos da família e outros grupos de relação mais direta.

França (2006) comenta que tomando como referência a escola e levando em consideração como ela trabalha, pode-se verificar que ela contribui para formação das representações que influenciam os hábitos de higiene corporal e ambiental dos seus alunos. No entanto, ela não é a única e pode não ser considerada a principal difusora para consolidar as representações de regras básicas de higiene no meio social, mas tem grande relevância neste sentido.

A escola não cumpre sozinha o papel de ensinar; e posteriormente, educar para a higiene, uma vez que o processo da higiene inicia-se em casa e ao educar para a saúde, de forma contextualizada e sistemática, o professor e a comunidade contribuem de maneira decisiva na formação de cidadãos capazes de atuar em favor da melhoria dos níveis de saúde pessoais e da coletividade.

Neste contexto, o ensino da higiene tem sido um desafio para a educação, no que se refere à possibilidade de garantir uma aprendizagem efetiva e transformadora de atitudes e hábitos que levam a uma vida saudável, porém é preciso educar levando em conta todos os aspectos envolvidos na formação de hábitos e atitudes que acontecem no dia-a-dia do aluno na escola e na sua comunidade. Sem dúvida, o professor sozinho não leva o aluno a adquirir todos os hábitos de higiene. Ele pode e deve, entretanto, fornecer elementos que capacitem para uma vida saudável.

Segundo os PCN (1997), nos anos iniciais devem ser desenvolvidas orientações de como cuidar do próprio corpo, sendo fundamental educar as crianças a ter uma vida saudável por meio dos bons hábitos de higiene. Portanto, o conhecimento sobre o corpo humano para o aluno deve estar associado a um melhor conhecimento do seu próprio corpo, por ser seu e por ser único, e com o qual ele tem uma intimidade e uma percepção subjetiva que ninguém mais pode ter. Essa visão favorece o desenvolvimento de atitudes de respeito e de apreço pelo próprio corpo e pelas diferenças individuais.

Igualmente a experimentação tem lugar de destaque nas Orientações Educacionais Complementares aos Parâmetros Curriculares Nacionais (PCN+, 2005):

A experimentação faz parte da vida, na escola ou no cotidiano de todos nós. Assim, a ideia de experimentação como atividade exclusiva das aulas de laboratório, onde os alunos recebem uma receita a ser seguida nos mínimos detalhes e cujos resultados já são previamente conhecidos, não condiz com o ensino atual. As atividades experimentais devem partir de um problema, de uma questão a ser respondida. Cabe ao professor orientar os alunos na busca de respostas. As questões propostas devem propiciar oportunidade para que os alunos elaborem hipóteses, testemnas, organizem os resultados obtidos, reflitam sobre o significado de resultados esperados e, sobretudo, o dos inesperados e usem as conclusões para a construção do conceito pretendido. Os caminhos podem ser diversos, e a liberdade para descobri-los é uma forte aliada na construção do conhecimento individual. As habilidades necessárias para que se desenvolva o espírito investigativo nos alunos não estão associadas a laboratórios modernos, com equipamentos sofisticados. Muitas vezes, experimentos simples, que podem ser realizados em casa, no pátio da escola ou na sala de aula, com materiais do dia-a-dia, levam a descobertas importantes. (PCN+ - Ciências da Natureza e Matemática, 2005, p.55)

A partir do exposto, no presente trabalho, investigaram-se as concepções espontâneas sobre higiene, em uma turma de 19 alunos de anos iniciais em uma escola privada de 
Cachoeira do Sul, Rio Grande do Sul, Brasil, além de propor uma metodologia lúdico experimental, buscando o ensino e a aprendizagem de crianças na área da saúde.

\section{Procedimentos Metodológicos}

A pesquisa foi desenvolvida em uma escola privada do município de Cachoeira do Sul, RS, com 19 alunos de terceiro ano do primeiro ciclo do ensino fundamental, sendo a faixa etária variável entre 8 e 10 anos, com condições sócio-econômicas favoráveis. O estudo propôs uma avaliação a partir de atividades experimentais com os envolvidos.

Para o experimento em questão foi utilizada tinta guache marrom (pois lembra cor de sujeira), tinta Neon para luz ultravioleta ("tinta invisível"), pincel, luz negra, sabonete líquido, papel toalha, água corrente e quatro maçãs. Como na turma havia 19 crianças, foi realizada a seguinte estratégia para realização do procedimento experimental. As crianças foram divididas em três grupos: grupo 1, composto por sete crianças; grupo 2, composto por 8 crianças e grupo 3, composto por quatro crianças.

Após a divisão nos grupos, foram pintadas as mãos dos alunos do grupo 1 com tinta guache marrom e as mãos dos alunos do grupo 2, com tinta invisível. Utilizou-se secador de cabelo para secagem da tinta nas mãos. As crianças foram questionadas sobre quais as mãos que estavam mais sujas. Após, as crianças foram submetidas à lavagem das mãos, sendo oferecida a elas, água corrente, sabonete líquido e papel toalha.

O grupo 3, composto por quatro integrantes, recebeu maçãs, também previamente pintadas, tendo sido adotada pintura de duas maçãs com tinta guache marrom e outras duas maçãs pintadas com tinta invisível. Igualmente foram pintadas as mãos destas quatro crianças, obedecendo aos mesmos critérios das maçãs. Posteriormente, foi solicitado a estes alunos para realizarem a lavagem de suas mãos e a lavagem das frutas.

Após todos terem lavado as mãos e as maçãs, passou-se individualmente em cada aluno, e em conjunto com o grupo investigado, realizou-se uma avaliação da lavagem realizada, sendo dividido em quatro graus: a) mãos ou maçãs muito bem lavadas (onde não se enxergasse nenhum vestígio de tinta), b) mãos ou maçãs bem lavadas (quando os vestígios de tinta fossem quase irrelevantes), c) mãos ou maças medianamente lavadas (onde aparecessem poucos vestígios de tinta) e d) mãos e maças mal lavadas (onde aparecessem vários vestígios de tinta). A observação da presença de tinta invisível contou com o auxílio de uma lâmpada de luz negra, sem que os alunos soubessem previamente que o que foi utilizado em suas mãos era tinta invisível.

De acordo com os resultados das lavagens pode-se analisar se os mesmos sabiam ou não lavar as mãos e as frutas. O tempo médio de lavagem das mãos e frutas foi verificado pelo uso do cronômetro.

Após as observações realizadas, foi discutido com as crianças o procedimento adequado da lavagem das mãos e dos alimentos. No término desta atividade, concluiu-se o processo com a execução da palestra.

Como continuação à atividade, os alunos construíram individualmente um texto e um desenho, onde foi solicitado que desenhassem sobre o experimento realizado e escrevessem o que aprenderam sobre o assunto.

O uso dos desenhos é descrito por BÖER $(1993,2007)$ e discute que a opção por este tipo de resposta se refere ao fato de que a livre expressão permitida pelo desenho, possibilita à pessoa manifestar, com espontaneidade, aquilo que é latente em seu interior, e que vai determinar sua ação exterior. Em outras palavras, o desenho é como uma fotografia externa que revela uma dimensão interna do indivíduo, e que é fruto das experiências de 
vida e aprendizagem que o aluno vivência e recebe no seu contexto social. A resposta por meio dos desenhos contém um conjunto de elementos com simbologia própria, passíveis de interpretações. Acredita-se que nos símbolos há uma linguagem através da qual a pessoa pode comunicar a maneira como ela interioriza e percebe um determinado assunto, naquele momento.

As folhas foram recolhidas e posteriormente analisadas. $O$ processo utilizado para compreender o pensamento discente sobre a temática apresentada referendou-se na Análise de Conteúdo (BARDIN, 1977), pois por meio dela tornou-se possível descrever, analisar e interpretar as ideias expressas nas entrevistas analisadas no estudo. De acordo com Bardin (1977), a categorização é uma operação de classificação de elementos constitutivos de um conjunto, por diferenciação e, seguidamente, por reagrupamento segundo o gênero (analogia). Deste modo, a análise de conteúdo categorial é alcançada por operações de desmembramento do texto em unidades, em categorias, segundo agrupamentos analógicos, e caracteriza-se por um processo estruturalista que classifica os elementos, segundo a investigação sobre o que cada um deles tem em comum. Ou seja, as categorias são rubricas ou classes, as quais reúnem um grupo de elementos (unidades de registro) sob um título genérico, em razão dos caracteres comuns apresentados por estes elementos. O procedimento inicial implica na decodificação dos dados contidos nos textos com descrição detalhada das ideias, ou estágio descritivo ou ainda análise categorial. Para essa autora, a análise de conteúdo compreende três pólos cronológicos: a) a pré-análise; b) a exploração do material e c) o tratamento dos resultados, a inferência e a interpretação.

$\mathrm{Na}$ redação deste trabalho recorreu-se à apresentação de alguns desenhos com o objetivo de ilustrar e substanciar as interpretações efetuadas.

\section{Resultados e discussão}

A análise global proveniente das concepções e relatos obtidos por meio da análise dos 19 textos construídos e desenhos feitos pelos alunos do terceiro ano permitiram inferir algumas considerações de como estes alunos compreendem a lavagem das mãos e alimentos e a importância da realização de atividades experimentais nos anos iniciais.

Durante e após a atividade prática desenvolvida, (Figuras 1 e 2), foi possível avaliar a lavagem das mãos dos participantes, podendo ser constatado na Tabela 1.

Os resultados demonstram que os alunos desconhecem o procedimento adequado para lavagem das mãos, implicando na permanência de microrganismos que possam vir a causar danos à saúde, pelo manuseio de alimentos, objetos ou a simples colocação das mãos em contato com a cavidade oral.

Tabela 1.- Resultados da avaliação das lavagens das mãos e das maçãs, realizadas pelos alunos do

\begin{tabular}{|c|c|c|c|c|c|}
\hline Classes & $\begin{array}{c}\text { Muito } \\
\text { bem } \\
\text { lavadas }\end{array}$ & $\begin{array}{c}\text { Bem } \\
\text { lavadas }\end{array}$ & $\begin{array}{c}\text { Medianamente } \\
\text { lavadas }\end{array}$ & $\begin{array}{c}\text { Mal } \\
\text { lavadas }\end{array}$ & $\begin{array}{c}\text { Tempo médio gasto } \\
\text { na lavagem }\end{array}$ \\
\hline Mãos com tinta guache & $0 \%$ & $28,57 \%$ & $71,43 \%$ & $0 \%$ & $50 \mathrm{seg}$ \\
\hline Mãos com tinta invisível & $0 \%$ & $0 \%$ & $12,5 \%$ & $87,5 \%$ & $30 \mathrm{seg}$ \\
\hline Maçãs com tinta guache & $0 \%$ & $0 \%$ & $0 \%$ & $100,0 \%$ & $60 \mathrm{seg}$ \\
\hline Maçãs com tinta invisível & $0 \%$ & $0 \%$ & $0 \%$ & $100,0 \%$ & $20 \mathrm{seg}$ \\
\hline
\end{tabular}


Com relação ao tempo médio gasto no procedimento de lavagem das mãos, os resultados obtidos estão relacionados ao fato de que os alunos que possuíam tinta guache em suas mãos puderam visualizá-la com maior facilidade, associando claramente a tinta com a sujeira, isto acarretou nas crianças o desejo de lavarem as mãos enquanto estas permanecessem sujas. $O$ mesmo fato não foi observado no grupo 2 (tinta invisível), pois os alunos por não observarem a tinta não possuíram o mesmo cuidado que o grupo anterior teve.

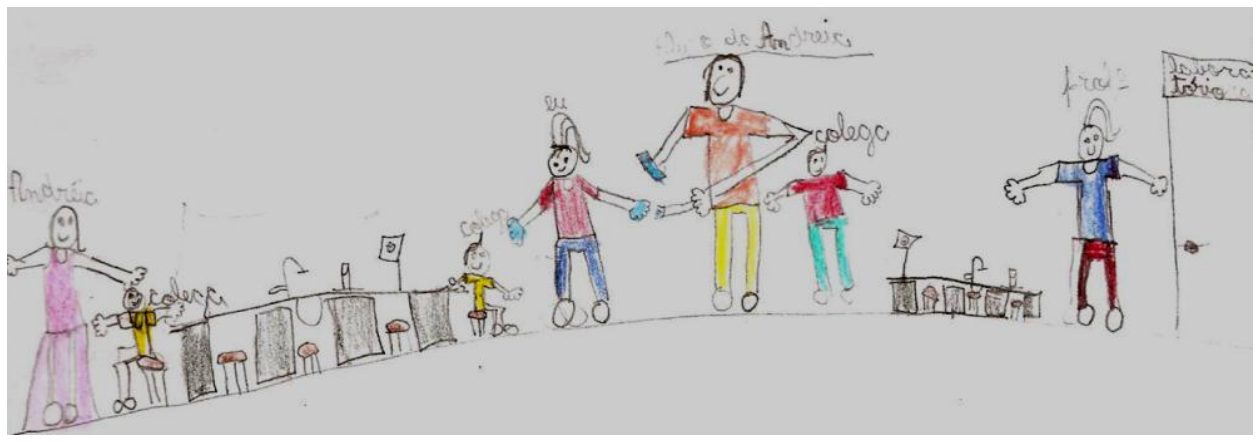

Figura 1.- Representação da atividade prática sobre a lavagem das mãos e lavagem de maçãs, realizada em laboratório com alunos de terceiro ano. Fonte: Goldschmidt (2012)
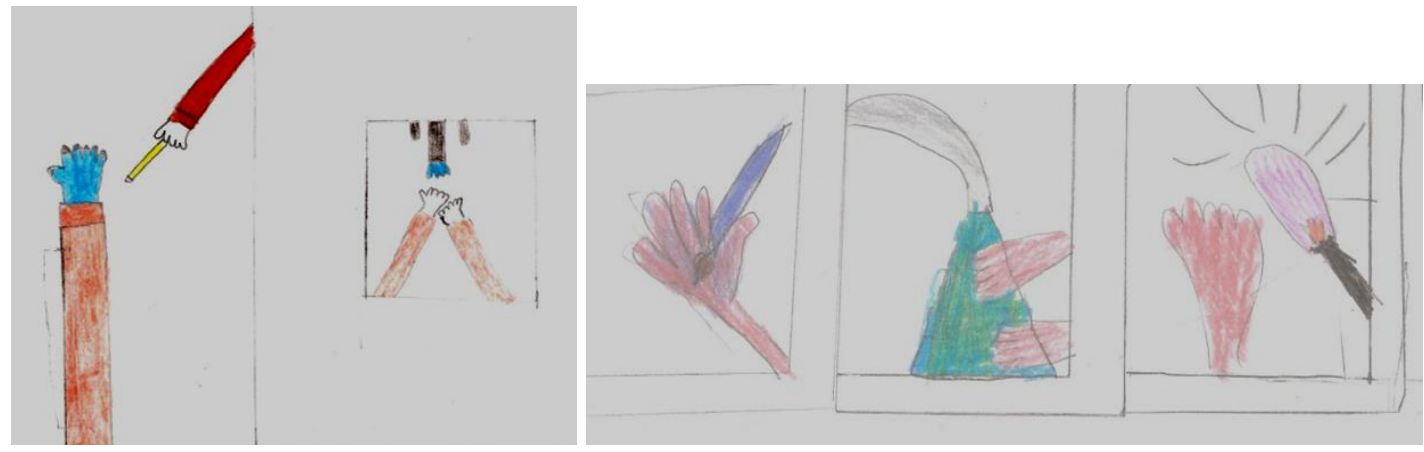

Figura 2.- Representação do uso da luz ultravioleta capaz de visualizar a presença da tinta invisível mesmo após a lavagem das mãos de alunos do terceiro ano. Fonte: Goldschmidt, A.I., 2012

A análise dos textos e desenhos produzidos pelos alunos permitiu agrupá-las em 12 categorias: lavagem das mãos antes a após situações distintas, lavagem das frutas e legumes/alimentos, descrição da experiência, satisfação com a experiência, satisfação com a palestra, compreensão do experimento, descrição do processo de lavagem adequada das mãos, higiene das unhas, higiene dos dentes, processo saúde-doença, citações dos produtos de higiene, hábitos de higiene diários (banho).

As categorias foram definidas a partir de análise prévia dos desenhos. Esta categorização pode ser evidenciada na Tabela 2.

A partir da análise dos textos e desenhos, podem-se inferir algumas considerações. Verificou-se que $21 \%$ dos relatos incluem citações que representam a descrição do experimento realizado, sendo observado que descreveram adequadamente a experimentação feita em laboratório como demonstra o relato de um aluno: "Na aula fomos ao quadro interativo e fizemos uma atividade sobre higiene. Depois fomos ao laboratório de ciências e sujamos as mãos e as maças e depois lavamos. A professora Andrea colocou uma lâmpada roxa em nossas mãos e as mãos estavam muito sujas ainda".

$\mathrm{Na}$ análise dos relatos, observou-se ainda o apontamento adequado da conduta científica, descrevendo adequadamente os passos da experimentação: "Ontem, dia 13 de 
abril, fomos no laboratório de ciências estudar a higiene pessoal. A professora Andreia nos ensinou a lavar as mãos corretamente. Seus ajudantes Vagner e Ângela pediram para uns alunos sujarem as mãos de tinta azul e os outros de tinta transparente, depois pediram para que nós lavássemos as mãos. Constatamos através de uma luz que não conseguimos lavar as mãos direitinho'.

Tabela 2.- Parcela de respostas associadas às categorias provenientes da análise de textos e imagens produzidos após a realização da atividade experimental.

\begin{tabular}{|l|c|}
\hline Categorias & Percentual \\
\hline Descrição da experiência & 21,0 \\
\hline Satisfação com a experiência & 10,5 \\
\hline Satisfação com a palestra & 5,3 \\
\hline Descrição do processo de lavagem adequada das mãos & 26,3 \\
\hline Citações dos produtos usados em higiene & 15,8 \\
\hline Compreensão sobre o experimento & 79,0 \\
\hline Lavagem das mãos antes e após situações distintas & 36,8 \\
\hline Lavagem das frutas e legumes/alimentos & 26,3 \\
\hline Processo Saúde-Doença & 36,8 \\
\hline Higiene das unhas & 5,3 \\
\hline Higiene dos dentes & 10,5 \\
\hline Hábitos de higiene diários (banho) & 15,8 \\
\hline
\end{tabular}

É importante ressaltar que as atividades práticas contribuem para a aprendizagem do aluno e têm sido executadas ou recomendadas para aplicação em ambiente escolar (CAVICCHI, 2008) e as crianças mostraram-se interessadas e participativas na experimentação, além de compreenderem a atividade desenvolvida.

Foi notável que a troca de ambiente, saindo do cotidiano e partindo para as dependências do laboratório de ciências, ocasionou nas crianças maior interação por proporcionar aos estudantes a oportunidade de participarem efetivamente na realização das técnicas aplicadas. Ao entrarem no laboratório estavam eufóricos, mostrando um comportamento bem diferente da entrada na sala audiovisual. Através da aplicação destas técnicas foi possível proporcionar aos alunos a possibilidade dos mesmos reconstruírem seus conhecimentos através da aprendizagem significativa.

Esta interação ocasionou não só uma mudança na estrutura cognitiva dos alunos como também um grande interesse, sendo notável a participação dos alunos durante a atividade. Foi demonstrada ainda através de algumas citações a satisfação dos alunos em estarem no laboratório, realizando as atividades práticas e o uso de metodologias diversificadas. Podese constatar isto através da citação: "Eu gostei muito da experiência, o que eu gostei mais foi quando ela colocou a lâmpada em nossas mãos e nós vimos onde estava a sujeira, foi muito legal. Eu gostei muito de ir no quadro interativo, foi muito legal, aprendi bastante, todas as experiências. Entendi que nossas mãos possuíam muitas sujeiras que a gente não vê e também micróbios". Esta descrição mostra o interesse e o aprendizado do tema pelos educandos, demonstrado o quanto é necessário para a prática pedagógica nos dias de hoje, que o professor compreenda a importância de práticas dinâmicas que juntamente com as técnicas usuais de ensino, tornam o aluno sujeito de seu aprendizado.

O mesmo interesse demonstrado pelos alunos nas experiências foi notado com relação à palestra. Isso possibilitou que ocorresse uma grande interação dos alunos no decorrer da palestra. Essa participação efetiva só foi possível a partir do momento que os alunos utilizaram seus conhecimentos prévios para confrontar as ideias passadas. Este debate tornou-se responsável para que ocorresse um confronto de ideias que de acordo com a 
teoria de Piaget é essencial para reconstrução de significados e necessário para o desenvolvimento de uma aprendizagem significativa.

Verificou-se que $26,3 \%$ dos alunos descreveram o processo de lavagem adequada das mãos, fazendo menção ao tempo e à importância em esfregar bem as mãos durante a lavagem: "Eu aprendi como é importante lavar as mãos e como esfregar elas, tem que esfregar os dedos e as mãos com sabão e água" e "Aprendi que nós devemos não só dar uma molhadinha nas mãos, nós temos que ficar pelo menos 3 minutos lavando as mãos. As vezes as pessoas, depois que elas saem do banheiro elas só dão uma lavadinha, elas acham que as suas mãos estão bem limpinhas, mas não estão, elas estão cheias de bactérias, por isso que a gente tem que lavar as mãos".

Os alunos reconhecem a necessidade de lavagem das mãos após distintas situações e não, apenas, antes de refeições (sendo apontado por 71,4\%) e após o uso do banheiro, que sem dúvida são as circunstâncias mais ressaltadas às crianças diariamente. Foram citadas ainda, em menor ocorrência, antes de dormir, antes de ir para o colégio, depois das refeições, depois de mexer em coisas sujas, com terra e areia e/ou tocar em animais e depois de brincar. Isto pode ser constatado na Tabela 3.

Tabela 3.- Apontamentos feitos pelos alunos de anos iniciais nos textos produzidos relacionados às situaç̃̃es que requerem lavagem das mãos

\begin{tabular}{|l|c|}
\hline \multicolumn{1}{|c|}{ Categorias } & Percentual \\
\hline Lavagem das mãos antes e após situações distintas & 100 \\
\hline - Antes das refeições & 71,4 \\
\hline - Antes de dormir & 28,6 \\
\hline - Antes de ir para o colégio & 14,3 \\
\hline - Depois das refeições & 14,3 \\
\hline - Após mexer em coisas sujas, terra, areia e/ou animais & 28,6 \\
\hline - Depois de brincar & 28,6 \\
\hline
\end{tabular}

No processo de aprendizagem iniciado nas dependências do lar, as crianças recebem noções básicas de higiene, em que a lavagem das mãos passa a ser uma das principais lições abordadas por pais e responsáveis no início do aprendizado infantil. Este processo está intimamente relacionado ao fato das crianças descobrirem o mundo através do tato, muitas vezes acabam não lavando as mãos corretamente antes das refeições, o que proporciona a ingestão de microrganismos patogênicos contidos nos alimentos a serem ingeridos. Sabendo da importância da lavagem das mãos observou-se que os alunos apresentaram dificuldade em realizar de maneira correta esse procedimento.

Souza e Morais (2000) afirmam que o objetivo da saúde escolar é atender a integralidade da criança. Em vez de considerarmos a criança com queixa escolar doente ou diferente, devemos vê-la de maneira a ser entendida no seu ambiente social mais amplo, na família, na escola, no seu grupo de amigos. Assim, é fundamental que os alunos conheçam bons hábitos, mas não basta apenas informá-los é preciso trabalhar de forma significativa a aquisição desses hábitos, para que dessa forma possam desenvolvê-los no seu ambiente de convivência. Assim, ao tratar de educar para higiene corporal, há de se buscar uma prática participativa de modo que as orientações para os alunos sejam coerentes com a linguagem do próprio corpo.

A presença do educador se torna imprescindível e fundamental, pois é preciso facilitar para que o aluno se aproprie do conhecimento científico a respeito do próprio corpo, sobre as condições de vida da população e sobre sua importância de colocar em prática certos hábitos que contribuirão decisivamente no cuidado com o corpo. Quando o aluno percebe 
que estes hábitos o ajudam a viver melhor, sem dúvida alguma ele estará motivado a colocá-la em prática com regularidade.

Diante disso, ressaltou-se de forma prática, o processo adequado de lavagem das mãos. Para tanto, demonstrou-se da seguinte forma: primeiramente retiraram-se anéis, pulseiras e relógio, abriu-se a torneira e se molhou as mãos sem encostar-se à pia. Colocou-se nas mãos aproximadamente 3 a $5 \mathrm{ml}$ de sabão, ensaboando e friccionando-as por aproximadamente 15 segundos, juntamente com a palma, o dorso com movimentos circulares, espaços interdigitais, articulações, polegar e extremidades dos dedos. Os antebraços foram lavados cuidadosamente, também por 15 segundos. O processo de enxágue foi realizado com água corrente abundante, retirando totalmente o resíduo do sabão, enxugando-se as mãos com papel toalha e ao fechar a torneira usou-se o cotovelo ou pode ser utilizado o papel toalha. Foi ensinado que esse procedimento deve ser realizado no período mínimo de 2 minutos.

Os participantes apontaram ainda em seus textos, o uso de produtos de higiene, bem como reconhecem hábitos higiênicos necessários no dia-a-dia.

Foi citado pelos alunos que, assim como a lavagem das mãos é necessária, também a lavagem de frutas e verduras antes de seu consumo, foi apontada por $26,3 \%$ dos alunos. Com relação à realização da técnica da lavagem das maçãs, pode ser observado, que os alunos designados a lavarem as maçãs com tinta guache demoraram um tempo superior do que os que estavam designados a lavarem as maçãs com tinta invisível. Isso ocorreu pelo motivo de que os alunos que possuíam as maçãs com tinta guache puderam visualizar a sujeira. Já as maçãs com tinta invisível foram lavadas em um período menor de tempo devido à falta de observação direta da sujeira.

Para obtermos uma boa lavagem de alimentos é preciso utilizar alguns produtos como vinagre ou água sanitária, além de água corrente. Foi ressaltada aos alunos a importância da lavagem correta de verduras, legumes e frutas, o que foi demonstrado com o uso de uma bacia com água sanitária.

Os alunos reconhecem que é preciso cortar as unhas para manter uma melhor higiene corporal, o que foi relatado por 5,3\% dos alunos quando descreveram que "devemos cortar as unhas quando estiverem grandes".

Foi discutido com os alunos durante a palestra sobre o corte periódico das unhas e que este deve ser feito respeitando a anatomia da mesma, deixando sempre uma margem de segurança de $2 \mathrm{~mm}$ de parte solta da unha, para evitar o despregamento da lâmina da unha do leito ungueal. Deve-se evitar cortar as laterais, para que não encravem pelo próprio erro do corte ou crescimento desordenado. Um fato importante é o problema descrito como unha encravada que ocorre devido ao mau corte da mesma.

A mesma importância foi dada à escovação dos dentes, em que se explicou sobre a importância de evitar o acúmulo de bactérias que formam um biofilme no qual podem se alimentar de restos de alimentos que permanecem depositados após as refeições. Assim, mantendo uma higiene bucal adequada podem ser evitadas doenças no trato bucal.

É importante salientar que $15,8 \%$ dos alunos citaram o banho diário como forma de prevenção de doenças, o que demonstra a compreensão sobre manter o corpo limpo. É de suma importância a abordagem deste tema, principalmente pela proximidade dos alunos nesta fase de sua vida e já que estão em fase de constante descoberta do seu corpo.

Os participantes demonstraram conhecimento associando a presença de microrganismos ao não cumprimento de hábitos de higiene e presença de microrganismos patogênicos. Esta associação foi evidenciada em 36,84\% dos alunos que escreveram: "Se não lavamos as mãos ao comer podemos ingerir os microorganismos e ficaremos doentes", "Precisamos esfregar muito bem as nossas mãos, porque quando pegamos nas coisas sujas 
sujamos nossas mãos com microorganismos que provocam doenças"; "Se a gente não lavar as mãos, a gente vai pegar micróbios e vai ficar doente". Como exemplificado nas citações, é notável que as crianças percebam os microrganismos como inimigos e não como agentes benéficos, sendo que a grande maioria dos microrganismos é benéfica, não causando danos à saúde, não ocasionando riscos. É importante salientar e discutir também estes conceitos com os alunos. Todos os indivíduos possuem a presença de fungos e bactérias convivendo em harmonia em nosso corpo.

Esta atividade serviu para que 78,3\% dos alunos pudessem compreender 0 experimento feito; ou seja, que mesmo eles não enxergando os microrganismos a olho nu, eles estão presentes em suas mãos. Demonstrando que a partir do momento em que a sujeira pode ser observada as crianças tomam um maior cuidado com a sua higienização (Figura 3).

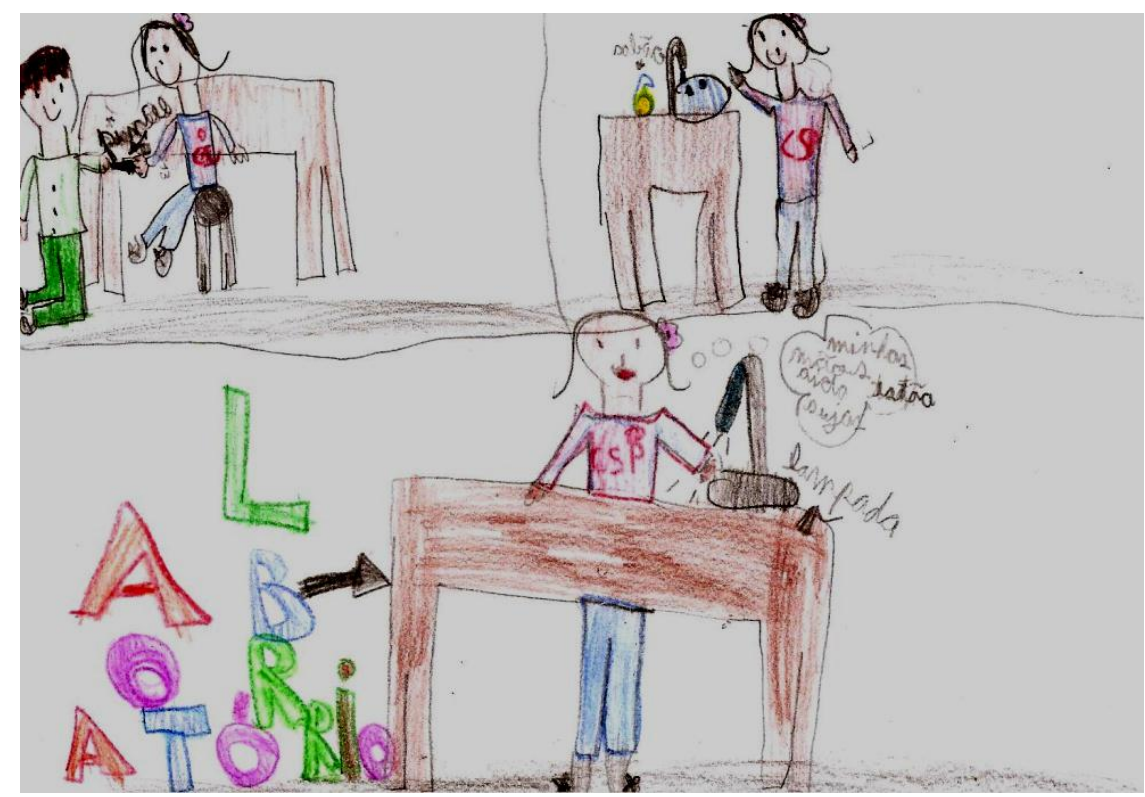

Figura 3.- Representação da atividade experimental e compreensão sobre a lavagem adequada das mãos pelos alunos do terceiro ano do ensino fundamental. Fonte: Goldschmidt (2012)

\section{Conclusões}

Pode-se observar no trabalho desenvolvido que os alunos possuem conhecimentos sobre a importância da lavagem adequada das mãos e dos alimentos. Estes hábitos estão intimamente ligados aos ensinamentos familiares, pois são expressos desde os primeiros meses de vida, passados de geração em geração, porém nem sempre, com técnicas apropriadas. Desta forma, crianças aprendem por repetição, mas não necessariamente compreendem a verdadeira importância de manter estes hábitos.

A partir do ingresso no meio escolar, o aluno adquire os ensinamentos trazidos pelo educador que são disseminados no interior da sala de aula, onde o aluno aprende a necessidade destes hábitos transmitidos por seus pais, ressignificando a importância da ligação entre a família e a escola no aprendizado dos educandos. Lembra-se também que não só o papel da família é importante, mas também o ensinamento trazido pelo professor é necessário, pois é através dele que se reformulam os conhecimentos prévios, os quais adquirem nova "roupagem" e são absorvidos de forma significativa.

Neste contexto vale lembrar que os conhecimentos prévios devem ser levados em consideração quando deparados com os conceitos científicos, muitas vezes tais saberes 
apresentam-se difíceis de modificar, porém cabe ao professor descobrir meios que chamem a atenção do aluno de modo que juntos construam o conhecimento. As práticas de higiene devem sempre ser lembradas quando o educador observar que algum aluno não está seguindo-a corretamente para que desta forma o mesmo não deixe de utilizá-la para seu próprio benefício.

A atividade recebeu grande aceitação por seus participantes, através de sua efetiva participação, em que os mesmos puderam interagir entre si na busca pelas respostas. Em relação a isto, é importante compreender que a construção do conhecimento também pode ser realizada de forma descontraída, cabendo ao educador a escolha correta de técnicas e métodos a serem empregados. Esta prática não está restrita aos grandes espaços físicos, podendo ser adequadas a qualquer ambiente escolar. Basta que o professor utilize sua criatividade e disponibilidade de horários para desenvolvê-la.

Neste contexto, o ensino de saúde tem sido um desafio para a educação, no que se refere à possibilidade de garantir uma aprendizagem efetiva e transformadora de atitudes e hábitos de vida. Ao educar para a saúde, de forma contextualizada e sistemática, o professor e a comunidade escolar contribuem de maneira decisiva na formação de cidadãos capazes de atuar em favor da melhoria dos níveis de saúde pessoais e da coletividade.

Os alunos necessitam de orientações de como cuidar do próprio corpo, sendo fundamental educá-los a ter uma vida saudável através dos bons hábitos de higiene, mas não basta apenas informá-los; é preciso trabalhar de forma significativa a aquisição desses hábitos, para que dessa forma possam desenvolvê-los no seu ambiente de convivência.

\section{Referências Bibliográficas}

AUSUBEL, D. P., NOVAK, J. e HANESIAN, H. Psicologia Educacional. Rio de Janeiro: Interamericana, 1980.

BARDIN, L. Análise de Conteúdo. Tradução de Luís Antero Reto e Augusto Pinheiro. Lisboa: Edições 70, 1977. 225p.

BOER, N.; Educação Ambiental em escolas de $1^{\circ}$ grau. Dissertação de Mestrado, Santa Maria: UFSM, 1993.

BOER, N.; Educação Ambiental e visões de mundo: uma análise pedagógica e epistemológica. Tese de Doutorado, Florianópolis: UFSC, 2007.

BRASIL. Secretaria da Educação Fundamental. Parâmetros curriculares nacionais: Ciências Naturais. Brasília: MEC/SEF.1997

BRASIL, Ministério da Educação. PCN+ Ensino Médio. Orientações Educacionais Complementares aos Parâmetros Curriculares Nacionais. Ciências da Natureza, Matemática e suas Tecnologias, 2005.

CAVICCHI, E. M. Historical Experiments in Student's hands: unfragmenting science trough action and history. Science and Education, 17, p 717-749, 2008.

DEMCZUK, O. M., SEPEL, L. M. N., LORETO, E. L. S. Investigação das concepções espontâneas referentes a ciclo de vida e suas implicações para o ensino nas series iniciais. Revista Electrónica de Enseñanza de las Ciencias, 6, 1, 117-128. 2007.

FRANÇA, M. C. A Educação Ambiental na escola: um estudo sobre as representações sociais dos professores do ensino fundamental do municipio de Pouso Redondo-SC. Dissertação de Mestrado em Educação. Universidade do Oeste de Santa Catarina: Joaçaba. 2006. 
SOUZA, B. DE P.; MORAIS, M. DE L. S. Saúde e Educação: Muito Prazer! - Novos Reinos no Atendimento à Queixa Escolar. São Paulo: Casa do Psicólogo, 2000.

TORTORI, T. R. A. A construção da aprendizagem significativa no ensino de ciências. In: Anais da $28^{a}$ Reunião Anual da Associação Nacional de Pesquisa e Pós-Graduação em Educação. MG: Caxambu. 2005. Em: http://www.anped.org.br 